\title{
Preliminary modelling of radionuclide migration in the argillaceous sediments of the Sumer Formation (Northwestern Bulgaria)
}

\author{
Dimitar Antonov, Madlena Tsvetkova, Doncho Karastanev
}

Geological Institute, Bulgarian Academy of Sciences, Acad. G. Bonchev Str., Bl. 24, 1113 Sofia, Bulgaria; e-mails:dimia@geology.bas.bg; mgeorgieva@geology.bas.bg; doncho@geology.bas.bg

(Accepted in revised form: November, 2020)

\begin{abstract}
In Bulgaria, from the preliminary analyses performed for site selection of deep geological disposal of high-level waste (HLW) and spent fuel (SF), it was concluded that the most promising host rocks are the argillaceous sediments of the Sumer Formation (Lower Cretaceous), situated in the Western ForeBalkan Mts. The present paper aims to compare the transport of three major radionuclides from a hypothetical radioactive waste disposal facility, which incorporates an engineering barrier of bentonite into the argillaceous (marl) medium. The simulations were performed by using HYDRUS-1D computer programme. The results are used for a preliminary estimation of argillaceous sediments as a host rock for geological disposal of HLW.
\end{abstract}

Antonov, D., Tsvetkova, M., Karastanev, D. 2020. Preliminary modelling of radionuclide migration in the argillaceous sediments of the Sumer Formation (Northwestern Bulgaria). Geologica Balcanica 49 (3), 13-18.

Keywords: HLW geological disposal facility, marls, numerical modelling.

\section{INTRODUCTION}

In Bulgaria, the present national strategy for RAW management (Council of Ministers, 2015) has not made a definitive decision on final disposal of highlevel waste (HLW) and spent fuel (SF), but deep geological disposal is considered to be the most ethical, sustainable and safe approach to the management of these wastes.

In the preliminary analyses performed for site selection of deep geological disposal of HLW and $\mathrm{SF}$, it was concluded that the argillaceous sedimentary formations in Northern Bulgaria are perspective in this regard. According to the safety requirements for the geological environment and the degree of knowledge, the most promising host rocks are the argillaceous sediments of the Sumer Formation (Lower Cretaceous), situated in the Western Fore-Balkan Mts (Karastanev et al., 2011). Besides, the latter rocks have previously been assessed as having good encapsulating properties during the exploration of gas fields in this region (Monahov and Monov, 1969).
In accordance with the IAEA documents, the HLW final disposal has to apply a multibarrier approach ("defence in depth") in order to ensure the safety of the storage facility during operation and the post-closure period (e.g., IAEA, 2006, IAEA, 2011a, b). Thus, being part of the approach, the main role in host rock selection for geological disposal requires the so-called safety assessment analysis, which includes model studies for an eventual migration of radionuclides from the repository (e.g., Mallants et al., 2001, 2011; IAEA, 2006, 2013). An initial step in such type of investigations is the elaboration of a hydraulic model of the argillaceous rocks of Sumer Formation and determination of the infiltration rate (flux) throughout the potential disposal zone of the Sumer Formation for thousands of years (Tsvetkova et al., 2019). To date, preliminary investigations concerning some aspects of the natural conditions of the site have been made, but a mass transport model, integrating the source (i.e., the disposed HLW), the engineer barrier and the argillaceous (marl) rocks with their specific characteristics, is not yet available. The aim of the study is to 
compare the migration of three major radionuclides from a hypothetical radioactive waste disposal facility, which incorporates an engineering barrier of bentonite into argillaceous medium.

\section{MATERIALS AND METHODS}

\section{Geosphere and repository schematization}

\section{Geological setting}

The accommodating environment of the potential storage system is composed of the marls of the Sumer Formation, representing a spatially sustained and significantly homogeneous geological environment with a total thickness of about 1,200 m (Fig. 1). It consists of dense clay marls with rare layers of sandstones, which were found in the upper part of the profile. In depth, the sandstones become even rarer, with small thicknesses, and laterally restricted. The marls have a very dense structure, composed of silt particles with clay-carbonate solder and variable carbonate content (Karastanev et al., 2011). The effective porosity is between 6\% and $8 \%$ (Georgieva, 2016). In the uppermost part of the profile, up to ten metres, the marls are weathered, but in depth they are dense and unaltered. With the exception of the uppermost part (the weathered zone), hydraulically the marls of the Sumer Formation represent an unsaturated medium.

\section{Assumed repository concept}

For the purpose of the current analysis, it is assumed that in the hypothetical repository situated at a depth interval of 335-350 m will be disposed $800 \mathrm{t}$ heavy metal in stainless containers. These containers with the respective HLW will be placed in a volume of $360 \mathrm{~m}^{3}$, which can be represented approximately as a cylindrical object situated horizontally with a circular cross-section area of $6 \mathrm{~m}^{2}$ and a length of $60 \mathrm{~m}$. Similarly to several scientific and technical publications (e.g., Westsik et al., 1983; IAEA, 2003; Sellin and Leupin, 2013; Kaufhold and Dohrmann, 2016), a bentonite engineering barrier around the canisters is introduced. The adopted herein bentonite barrier is situated around the general cylindrical body with HLW and has a thickness of $6 \mathrm{~m}$ all around it. This barrier, together with the storage canisters, can also be represented as a cylindrical body with a volume of $12,297 \mathrm{~m}^{3}$.

According to Oversby (1986), one hundred years after the disposal of HLW from Pressurized Water Reactor type (as Kozloduy NPP), some of the main radionuclides are: ${ }^{137} \mathrm{Cs}$ with activity of 10,300 Ci/MTHM (curie per metric ton of heavy metal); ${ }^{90} \mathrm{Sr}$ with activity of $6,710 \mathrm{Ci} / \mathrm{MTHM}$; ${ }^{241} \mathrm{Am}$ with activity of $3,750 \mathrm{Ci} / \mathrm{MTHM}$. These isotopes are selected to be the subject of simulations in the present study. As a scenario for the applied modelling procedure, for the repository plus the bentonite barrier, an effective medium porosity of $10 \%$ is arbitrarily used, which after 100 years of operation of the storage will be filled with dissolved radionuclides. This assumption is actually part of the so-called conservative approach that takes into account the most unfavourable value in the case of porosity. Based on the above data and parameters of the storage facility, the following

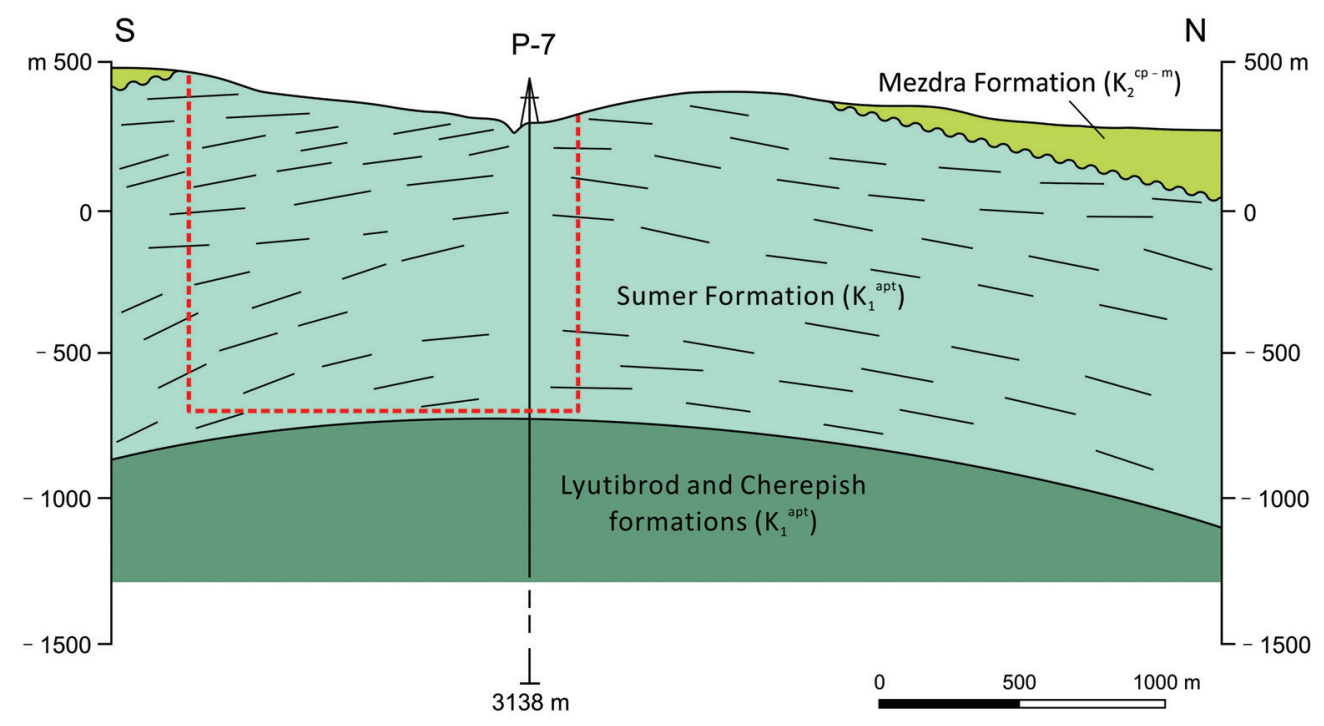

Fig. 1. Potential zone (red dotted line) for optional geological repository of radioactive waste in the Sumer Formation. 
concentrations are obtained for the three radionuclides (Table 1).

\section{Formulation of the hydraulic (water flow) model}

The hydraulic model of the Sumer Formation at the specific site was already a subject to previous investigation (Tsvetkova et al., 2019). In brief, the simulations showed that, at this low porosity $(6-8 \%)$ and large thickness of the marl massif (about $1200 \mathrm{~m}$ ), the main parameter that controls the water transport is the permeability of the porous medium. The water flow, after establishing a "quasi-equilibrium state", takes place at a speed of $1.73 \times 10^{-6} \mathrm{~m} / \mathrm{d}\left(2.0 \times 10^{-11} \mathrm{~m} / \mathrm{s}\right)$. This equilibrium state occurs after 940 years from the beginning of the simulations for the whole simulation domain of $400 \mathrm{~m}$.

\section{Formulation of the mass transport model}

Based on the geological settings of the investigated site, as well as the position of the storage facility, one-dimensional convective-dispersive model of the water flow describing the transport of mutually independent solutes being subject to decay processes has been used. In this model, the retardation properties of the engineered layers and argillaceous sediments are described by the so-called distribution coefficient $\mathrm{K}_{\mathrm{d}}$. Such a model has been applied in similar studies, both in Bulgaria (Stoyanov, 2012, 2019; Kotsev et al., 2018) and elsewhere (e.g., Robinson and Bussod, 2000; Mallants et al., 2001, 2011; Šimůnek et al., 2006; Merk, 2012).

\section{Elements of the Mass Transport Field (Model)}

In order to perform a complete assessment of the radionuclide migration in the argillaceous sediments of the Sumer Formation, the following elements were considered in one-dimension vertical model with particular characteristics: from $0 \mathrm{~m}$ to $335 \mathrm{~m}$ below the surface - argillaceous sediments (Sumer Formation); from $335 \mathrm{~m}$ to $350 \mathrm{~m}$ - repository with engineered barrier; and from $350 \mathrm{~m}$ to $400 \mathrm{~m}$ - argillaceous sediments. In addition, mass transport parameters of the selected three key radionuclides were also taken into account (see Table 2). The constructed model was implemented in computer code HYDRUS-1D (Šimůnek et al., 2008) numerically solving the partial differential equations for the convective-dispersive equations.

\section{RESULTS}

In order to illustrate the results obtained, in the model study for all three radionuclides, "observation nodes" were selected at three specific points in the simulation profile: 1 ) exactly at the bottom of

Table 1

Sample radionuclide inventory and concentrations after 100 years from the disposal of HLW

\begin{tabular}{ccccc}
\hline \multirow{2}{*}{ Radionuclide } & $\begin{array}{c}\text { Activity after 100 years after } \\
\text { disposal for MTHM }\end{array}$ & $\begin{array}{c}\text { Total weight of } \\
\text { wastes }\end{array}$ & Total activity & $\begin{array}{c}\text { Concentration in the } \\
\text { solute phase }\end{array}$ \\
\cline { 2 - 5 } & $\mathrm{Bq}$ & MTHM & $\mathrm{Bq}$ & $\mathrm{Bq} / \mathrm{m}^{3}$ \\
\hline${ }^{137} \mathrm{Cs}$ & $3.8110 \times 10^{14}$ & 803664 & $3.0626 \times 10^{17}$ & $2.4908 \times 10^{12}$ \\
${ }^{90} \mathrm{Sr}$ & $2.4827 \times 10^{14}$ & 803664 & $1.9953 \times 10^{17}$ & $1.6226 \times 10^{12}$ \\
${ }^{241} \mathrm{Am}$ & $1.3875 \times 10^{14}$ & 803664 & $1.1151 \times 10^{17}$ & $9.0683 \times 10^{11}$ \\
\hline
\end{tabular}

Table 2

Basic parameters characterizing the behaviour and transport of the considered radionuclides

\begin{tabular}{cccc}
\hline \multirow{2}{*}{ Radionuclide } & Decay constant, $\lambda$ & $\begin{array}{c}\text { Distribution coefficient } \mathrm{K}_{\mathrm{d}} \\
\text { for the bentonite barrier }\end{array}$ & $\begin{array}{c}\text { Distribution coefficient } \mathrm{K}_{\mathrm{d}} \\
\text { for marls** }\end{array}$ \\
\cline { 2 - 4 } & $1 / \mathrm{d}$ & $\mathrm{m}^{3} / \mathrm{kg}$ & $\mathrm{m}^{3} / \mathrm{kg}$ \\
\hline${ }^{137} \mathrm{Cs}$ & $6.29 \times 10^{-5}$ & 0.33 & 0.15 \\
${ }^{90} \mathrm{Sr}$ & $6.55 \times 10^{-5}$ & 0.39 & 0.16 \\
${ }^{241} \mathrm{Am}$ & $4.39 \times 10^{-5}$ & 30.00 & 8.00 \\
\hline
\end{tabular}

*The values given are for clays from Thibault et al. (1990).

**The values for the distribution coefficient are determined on the basis of specialized literature data (EPA, 1999, 2004) and are consistent with the mineral and chemical composition of the marls. 
Table 3

Maximum $C_{\max }$ and minimum $C_{\min }$ concentrations in the solute phase of the investigated radionuclides for the whole period of simulation at the three observation nodes' depths

\begin{tabular}{cccc}
\hline \multirow{2}{*}{$\begin{array}{c}\text { Observation node (distance } \\
\text { from the surface) }\end{array}$} & ${ }^{137} \mathrm{Cs}$ & ${ }^{90} \mathrm{Sr}$ & ${ }^{241} \mathrm{Am}$ \\
\cline { 2 - 4 } & $C_{\max }-C_{\min }\left[\mathrm{Bq} / \mathrm{m}^{3}\right]$ & $C_{\max }-C_{\min }\left[\mathrm{Bq} / \mathrm{m}^{3}\right]$ & $C_{\max }-C_{\min }\left[\mathrm{Bq} / \mathrm{m}^{3}\right]$ \\
\hline $1(350 \mathrm{~m})$ & $2.49 \times 10^{12}-0$ & $1.62 \times 10^{12}-0$ & $9.07 \times 10^{11}-0$ \\
$2(351 \mathrm{~m})$ & $6.12 \times 10^{8}-0$ & $4.55 \times 10^{8}-0$ & $2.40 \times 10^{8}-0$ \\
$3(355 \mathrm{~m})$ & $0-0$ & $0-0$ & $0-0$ \\
\hline
\end{tabular}

the storage facility; 2) one metre below the storage facility (in the marl domain); and 3) five metres below the facility with the presumption that the main pathway of radionuclide transport is downwards. So as to compare the results, the maximum and minimum concentrations $\left(C_{\max }\right.$ and $\left.C_{\min }\right)$ of the three radionuclides at the three points were also represented (Table 3). The simulations show that, at the bottom of the storage facility, the maximum

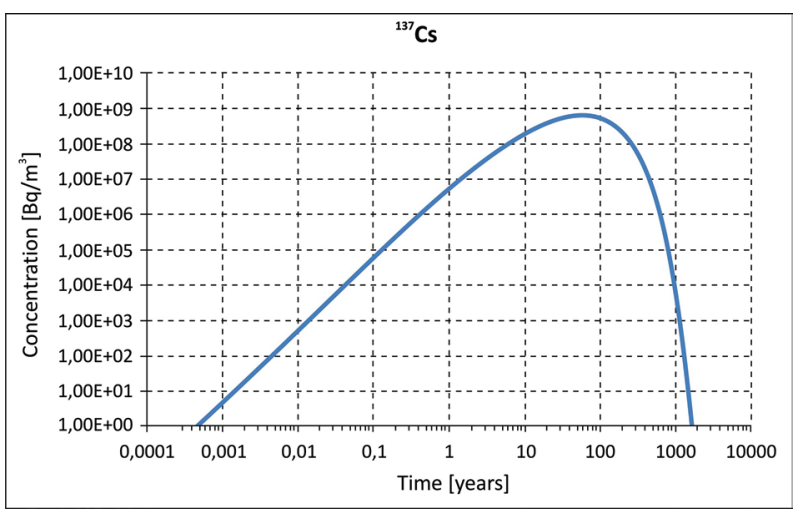

Fig. 2. Cesium concentration in solute phase vs time at $1 \mathrm{~m}$ below the bottom of the storage facility.

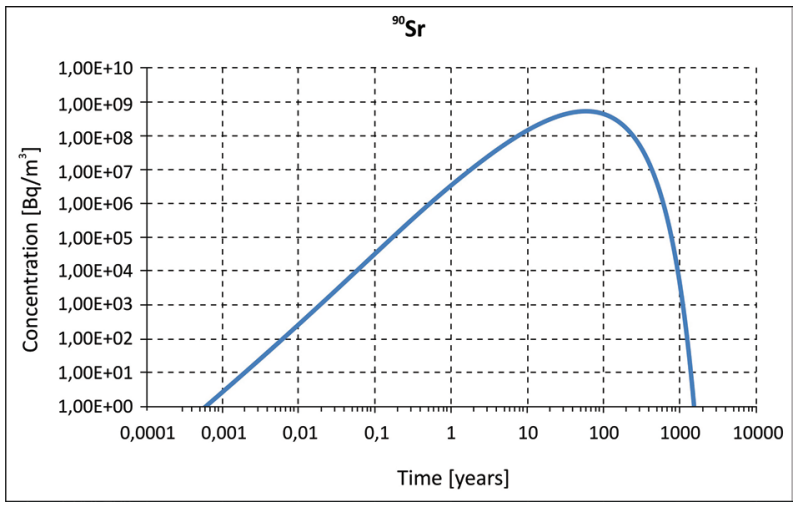

Fig. 3. Strontium concentration in solute phase vs time at $1 \mathrm{~m}$ below the bottom of the storage facility. concentrations, coinciding with the initial concentrations, decrease to "zero" for the three radionuclides for the period of investigation, as the period of simulation is 10,000 years for ${ }^{137} \mathrm{Cs}$ and ${ }^{90} \mathrm{Sr}$; and 100,000 for ${ }^{241} \mathrm{Am}$, respectively. The time of zero concentration for $\mathrm{Cs}$, $\mathrm{Sr}$ and Am, respectively, is after 1,980 years, 1,854 years and 28,049 years. It should be noted that, for this particular study, the "zero concentration" was assumed as less than $1 \mathrm{~Bq} / \mathrm{m}^{3}$.

At one metre below the facility, the peak values of concentrations are between three and four times of magnitude lower than the initial ones (Table 3). For Cs, the peak value of $6.12 \times 10^{8} \mathrm{~Bq} / \mathrm{m}^{3}$ (almost four orders of magnitude lower) was obtained after 66 years and "zero concentration" was obtained after 1,644 years (Fig. 2). For Sr, the peak value of $4.55 \times 10^{8} \mathrm{~Bq} / \mathrm{m}^{3}$ (about three and a half orders of magnitude lower) was obtained after 60 years and "zero concentration" was obtained after 1,542 years (Fig. 3). For Am, the peak value of $2.40 \times 10^{8} \mathrm{~Bq} / \mathrm{m}^{3}$ (almost four orders of magnitude lower) was obtained after 929 years and "zero concentration" was obtained after 23,069 years (Fig. 4).

At $5 \mathrm{~m}$ below the storage facility, the concentrations are "zero" during the whole period of simula-

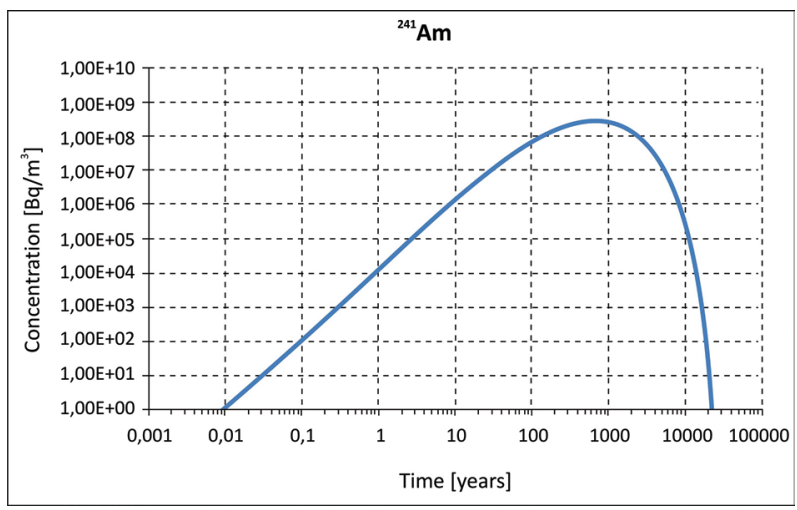

Fig. 4. Americium concentration in solute phase vs time at $1 \mathrm{~m}$ below the bottom of the storage facility. 
tions, i.e., 10,000 years for Cs and Sr and 100,000 years for Am (Table 3). In addition, the relative errors in the solute mass balance of the entire flow domain for the three simulations are very reasonable: $2.98 \%$ for ${ }^{137} \mathrm{Cs}$; $3.09 \%$ for ${ }^{90} \mathrm{Sr}$; and $2.89 \%$ for ${ }^{241} \mathrm{Am}$. Hence, the performed mass transport model is mathematically verified. Therefore, marls are a promising domain as a deep geological disposal medium, but stating that this study is a preliminary attempt to characterize the Sumer Formation. It should note that the results for the concentration of radionuclides are based on officially published data and simulations of numerical modeling.

\section{CONCLUSION}

The comparison of the transport of three main radionuclides at $1 \mathrm{~m}$ below the repository shows that they will decrease their concentration activ- ity as subject to the decay processes and retardation properties of the storage facility and marl medium with about three orders of magnitude. In addition, at $5 \mathrm{~m}$ under the storage facility, the concentrations are zero for the whole period of simulations. Thus, an eventual repository for HLW hosted in the argillaceous sediments of the Sumer Formation will function for thousands of years in a safe manner from the viewpoint of the investigated radionuclides (or others with similar parameters).

\section{Acknowledgements}

The authors are grateful to official journal reviewers Prof. Maria Datcheva (Institute of Mechanics, Bulgarian Academy of Sciences) and Prof. Kimihito Nakamura (Kyoto University, Japan) for their highly constructive suggestions and comments on an early version of the manuscript.

\section{REFERENCES}

Council of Ministers. 2015. Revised Strategy for Spent Fuel and Radioactive Waste Management till 2030. Protocol 35, Article 31 of the Council of Ministers, Sofia, 68 pp. (in Bulgarian).

Environmental Protection Agency. 1999. Understanding Variation in Partition Coefficient, $K_{d}$, Values. Volume II: Review of Geochemistry and Available $K_{d}$ Values for Cadmium, Cesium, Chromium, Lead, Plutonium, Radon, Strontium, Thorium, Tritium (3H), and Uranium. EPA 402-R99-004B, Washington DC, 341 pp.

Environmental Protection Agency. 2004. Understanding Variation in Partition Coefficient, $K_{d}$, Values. Volume III: Review of Geochemistry and Available $K_{d}$ Values for Americium, Arsenic, Curium, Iodine, Neptunium, Radium, and Technetium. EPA 402-R-04-002C, Washington DC, 188 pp.

Georgieva, M. 2016. Effective porosity and mineral composition of marl from the Sumer Formation. Bulgarian Geological Society, National Conference with International Participation "Geosciences 2016", Abstracts, 147-148 (in Bulgarian, with English abstract).

International Atomic Energy Agency. 2003. Scientific and Technical Basis for the Geological Disposal of Radioactive Wastes. IAEA Technical Reports Series Nr 413, Vienna, $90 \mathrm{pp}$.

International Atomic Energy Agency. 2006. Fundamental safety principles: Safety fundamentals. IAEA Safety Standards Series Nr SF-1, IAEA, Vienna, 24 pp.

International Atomic Energy Agency. 2011a. Disposal of radioactive waste. IAEA Safety Standards Series Nr SSR-5, Vienna, 62 pp.

International Atomic Energy Agency. 2011b. Geological disposal facilities for Radioactive Waste. IAEA Specific Safety Guide Nr SSG-14, Vienna, 124 pp.
International Atomic Energy Agency. 2013. The Use of numerical models in support of site characterization and performance assessment studies of geological repositories. IAEA TecDoc Series Nr 1717, Vienna, 134 pp.

Karastanev, D., Evstatiev, D., Stoykova, K., Nakov, R., Benderev, A., Radulov, A., Solakov, D., Todorov, K., Vasilev, E., Ivanov, P. 2011. Study of the Possibilities for Implementing Deep Geological Disposal. Task 4 - Analysis and Zonation of the Territory of Bulgaria, Selection of Potential Host Rocks for Deep RAW Disposal. Contract Report (SERAW Nr 208041), 432 pp. (in Bulgarian, unpublished).

Kaufhold, S., Dohrmann, R. 2016. Distinguishing between more and less suitable bentonites for storage of high-level radioactive waste. Clay Minerals 51 (2), 289-302.

Kotsev, T., Kolev, S., Hristov, V. 2018. Modelling of groundwater flow and transport of pollutants caused by a difference in groundwater densities (on the example of the valley of Vulche dere creek, downstream of Eleshnitsa tailings pond). Engineering Geology and Hydrogeology 32, 3-12 (in Bulgarian, with English abstract).

Mallants, D., Marivoet, J., Sillen, X. 2001. Performance assessment of the disposal of vitrified high-level waste in a clay layer. Journal of Nuclear Materials 298 (1-2), 125-135.

Mallants, D., van Genuchten, M.T., Šimůnek, J., Jacques, D., Seetharam, S. 2011. Leaching of contaminants to groundwater. In: Swartjes, F.A. (Ed), Dealing with Contaminated Sites. Springer, Dordrecht, 787-850.

Monahov, I., Monov, B. 1969. New Tectonic Data of the Chiren Structure. Review of the Bulgarian Geological Society 30 (2), 219-223 (in Bulgarian).

Merk, R. 2012. Numerical modeling of the radionuclide water pathway with HYDRUS and comparison with the IAEA model of SR 44. Journal of Environmental Radioactivity 105, 60-69. 
Oversby, V. 1986. Important Radionuclides in High Level Nuclear Waste Disposal: Determination Using a Comparison of the EPA and NRC Regulations. Lawrence Livermore National Laboratory, UCRL Preprint 94222, 32 pp.

Robinson, B.A., Bussod, G.Y. 2000. Radionuclide transport in the unsaturated zone at Yucca Mountain: Numerical model and preliminary field observations. In: Faybishenko, B., Witherspoon, P.A., Benson, S.M. (Eds), Dynamics of Fluids in Fractured Rock. Geophysical Monograph 122. American Geophysical Union, Washington, D. C., 323-336.

Sellin, P., Leupin, O.X. 2013. The Use of Clay as an Engineered Barrier in Radioactive-Waste Management a Review. Clays and Clay Minerals 61, 477-498.

Šimůnek, J., Jacques, D., van Genuchten, M.Th., Mallants, D. 2006. Multicomponent geochemical transport modeling using HYDRUS-1D and HP1. Journal of the American Water Resources Association 42 (6), 1537-1547.

Šimůnek, J., Šejna, M., Saito, H., Sakai, M., van Genuchten, M.Th. 2008. The Hydrus-1D Software Package for Simulating the Movement of Water, Heat, and Multiple Solutes in Variably Saturated Media. Version 4.0. HYDRUS Software Series 3, Riverside California: Department of Environmental Sciences, University of California Riverside, 315 pp.
Stoyanov, N.T. 2012. Model studies estimating the risk of a possible pollution in geological basis and groundwater caused by the designed National disposal facility for storage of radioactive waste in the region of NPS "Kozlodui”. Annual of the University of Mining and Geology 55 (1), 140-145 (in Bulgarian, with English abstract).

Stoyanov, N.T. 2019. Mathematical modelling in hydrogeology. Numerical 3D models using finite difference method. Publishing house "V. Nedkov", Sofia, 246 pp. (in Bulgarian).

Thibault, D.H., Sheppard, M.I., Smith, P.A. 1990. A Critical Compilation and Review of Default Soil Solid/Liquid Partition Coefficients, $K_{d}$, for Use in Environmental Assessments. AECL-10125, Whiteshell Nuclear Research Establishment, Atomic Energy of Canada, Manitoba, 114 pp.

Tsvetkova, M., Antonov, D., Karastanev, D. 2019. Modelbased estimation of the moisture regime of the marls from the Sumer Formation, Northwestern Bulgaria. Review of the Bulgarian Geological Society 80 (3), 194-196 (in Bulgarian, with English abstract).

Westsik, J.H., Hodges, F.N., Kuhn, W.L., Myers, T.R. 1983. Water migration through compacted bentonite backfills for containment of high-level nuclear waste. Nuclear and Chemical Waste Management 4 (4), 291-299. 